\title{
Assessment of absolute partial discharge intensity from a free-space radiometric measurement.
}

\author{
JABER, A., LAZARIDIS, P., ZHANG, Y., SAEED, B., KHAN, U., UPTON, D., \\ AHMED, H., MATHER, P., VIEIRA, M.F.Q., ATKINSON, R., JUDD, M. and \\ GLOVER, I.A.
}

(C) 2016 IEEE. Personal use of this material is permitted. Permission from IEEE must be obtained for all other uses, in any current or future media, including reprinting/republishing this material for advertising or promotional purposes, creating new collective works, for resale or redistribution to servers or lists, or reuse of any copyrighted component of this work in other works.

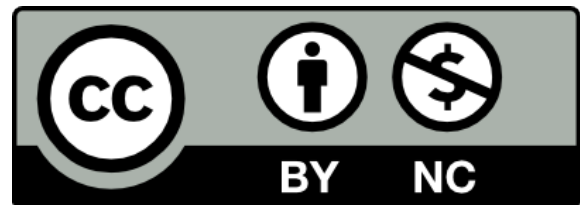




\title{
Assessment of Absolute Partial Discharge Intensity from a Free-space Radiometric Measurement
}

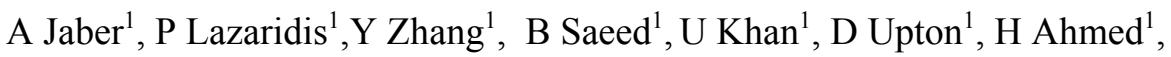 \\ P Mather $^{1}$, M F Q Vieira ${ }^{2}$, R Atkinson ${ }^{3}, \mathrm{M} \mathrm{Judd}^{4}$, and I A Glover ${ }^{1}$ \\ ${ }^{1}$ Department of Engineering \& Technology, University of Huddersfield, Huddersfield HD1 3DH, UK \\ ${ }^{2}$ Department of Electrical Engineering, Universidade Federal de Campina Grande, Campina Grande, Brazil \\ ${ }^{3}$ Deptartment of Electronic and Electrical Engineering, University of Strathclyde, Glasgow G1 1XW, UK \\ ${ }^{4}$ High Frequency Diagnostics \& Engineering Ltd, Glasgow G2 6HJ, UK \\ E-mail: Adel.Jaber@hud.ac.uk
}

\begin{abstract}
Partial discharge (PD) is measured simultaneously using free-space radiometric (FSR) and a galvanic contact measurement technique based on the IEC 60270 standard. The PD source is an emulator of the floating-electrode type. The radiated signal is captured using a biconical antenna. A method of estimating absolute partial discharge (PD) activity level from a radiometric measurement by relating effective radiated power to PD intensity using a PD calibration device is presented.
\end{abstract}

Keywords- Partial discharge; free space radiometric measurement; galvanic contact measurement; PD calibration.

\section{INTRODUCTION}

Measurement of partial discharge (PD) is an important tool in the monitoring of insulation integrity in high voltage (HV) equipment. $\mathrm{PD}$ has traditionally been detected by contact (especially IEC 60270) and capacitive/inductive coupling methods. The free-space radiometric (FSR) detection of PD is a relatively new technique. The work reported in this paper addresses the calibration of a floating-electrode PD source required for the development of a PD wireless sensor network (WSN). The calibration of the source suggests the possibility of using free space radiometric measurements to estimate the absolute intensity of PD in HV insulation integrity monitoring applications.

\section{APPARATUS}

The apparatus used to simultaneously capture FSR and galvanic contact measurements is shown in Figure 1.

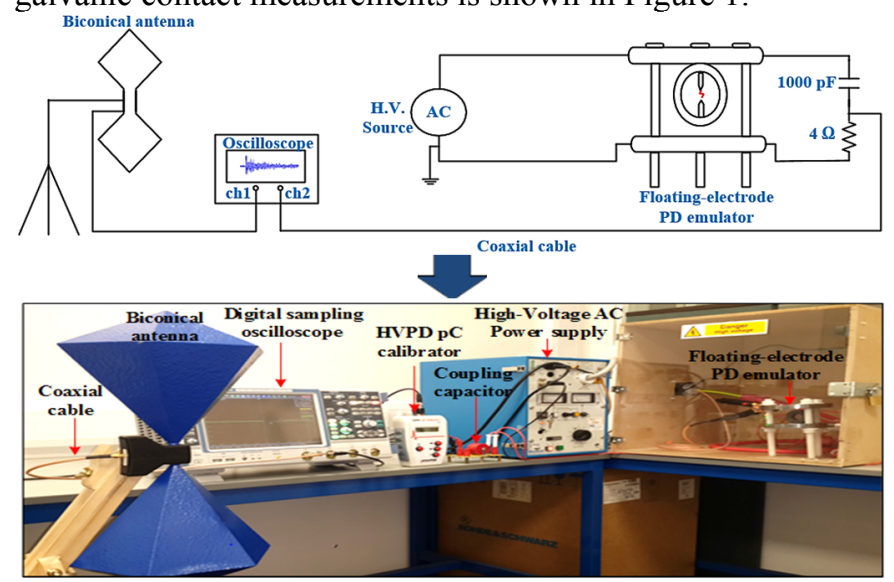

Fig. 1. PD measurement apparatus.
PD is generated by applying an HV sinusoid to the floatingelectrode PD emulator. The PD emulator, shown in Figure 2, has $0.60 \mathrm{~mm}$ and $6.2 \mathrm{~cm}$ gaps on either side of the floating electrode. The voltage rating of the $1000 \mathrm{pF}$ coupling capacitor (shown in Figure 1) used to make the galvanic PD measurements is $40 \mathrm{kV}$. When the electric field is sufficiently large PD occurs across the smaller of the floating electrode gaps $[1,2]$.

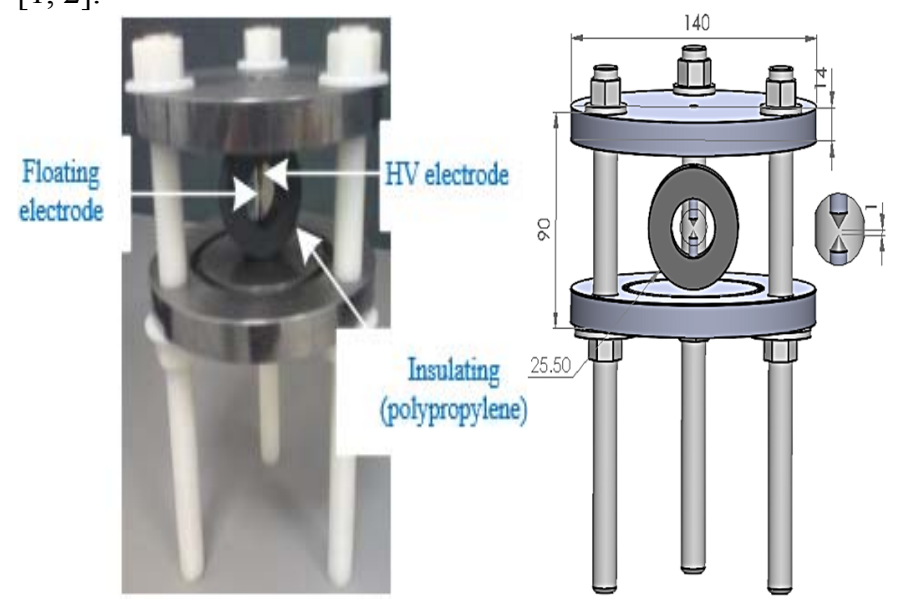

Fig. 2. Floating-electrode PD emulator (dimensions in $\mathrm{mm}$ ).

The radiometric measurements were made using a biconical antenna connected to a $4 \mathrm{GHz}, 20 \mathrm{GSa} / \mathrm{s}$, digital sampling oscilloscope (DSO). The antenna (Figure 3,) was vertically polarised.

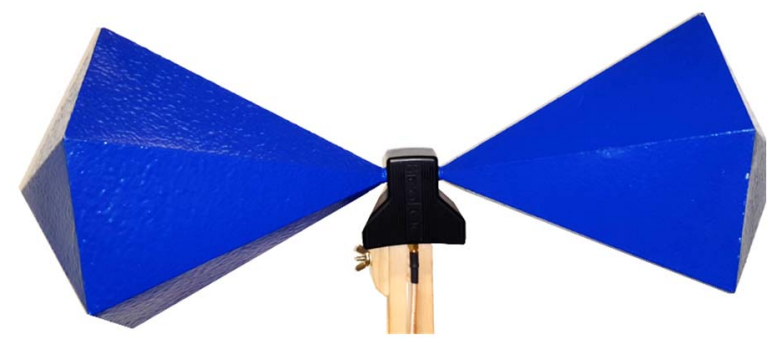

Fig. 3. Biconical antenna used in the FSR measurements.

The frequency range of the antenna is $20 \mathrm{MHz}$ to $1 \mathrm{GHz}$ and tts nominal impedance is $50 \mathrm{ohms}$. The antenna gain at $100 \mathrm{MHz}$ is around $-9 \mathrm{dBi}$ and its dimensions are $540 \mathrm{~mm} \times 225 \mathrm{~mm} \times 225$ $\mathrm{mm}$. 
A commercial PD calibration device has been used to assess the ERP of the emulator as a function of PD apparent charge. The off-line HVPD $\mathrm{pC}$ calibrator is designed to provide a range of current pulses of specified charge from $1 \mathrm{pC}$ up to $100 \mathrm{nC}$. Figure 4 shows the calibrator [3].

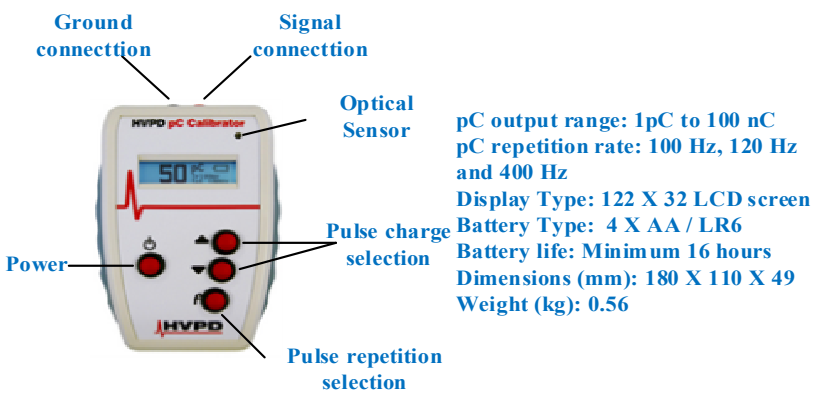

Fig. 4. HVPD pC calibrator with specification [3].

\section{PD CALIBRATION}

PD intensity, or strength, is specified by the apparent charge transferred during a discharge event. It is typically measured in picocoulombs or nanocoulombs. Strictly, the apparent charge is that charge which, if injected into the terminals of the device under investigation, would result in the same response of the measurement instrument as the response to the PD event [4].

Figure 5 is a plot of the integral of the current pulse resulting from the range of calibration pulses as provided by the calibration device. The pulses were measured using a digital sampling oscilloscope (DSO) with an input impedance of 1 $\mathrm{M} \Omega$.

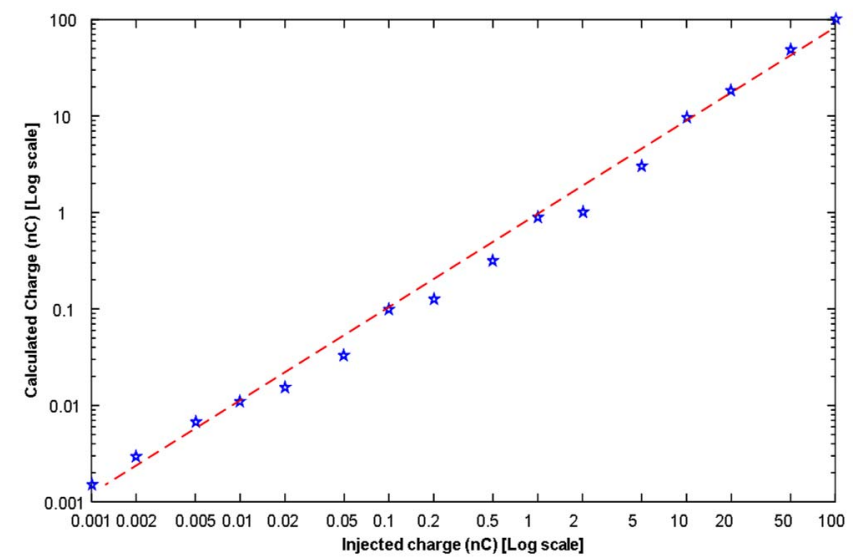

Fig. 5. Integral of measured current pulse (calculated charge) versus calbration device injected charge.

Classical PD measurements, as described in [5], use a galvanic connection to conduct the PD current pulse (or a voltage pulse that is proportional to the current pulse) via a cable to the measurement instrument. If the measurement is sufficiently broadband for the pulse to remain baseband in nature then it is easily, and unambiguously, integrated to find the apparent charge. If the pulse oscillates due to inductance and capacitance of the PD-source/measurement-system combination, however, then the question arises as to how best to assess the apparent charge. The integral from the start of the measured pulse to its first zero crossing has been used as a measure of apparent charge [6]. This metric has been investigated by comparing it with a range of known charges injected into the emulator using the HVPC calibrator. The measurement circuit is shown in Figure 6. A typical observed waveform is shown in Figure 7.

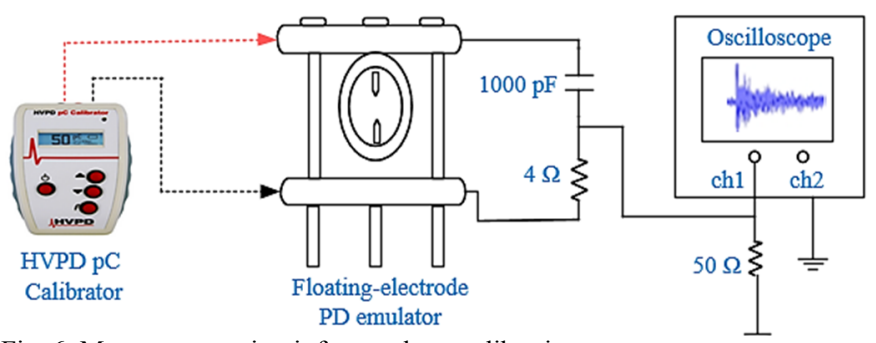

Fig. 6. Measurement circuit for emulator calibration.

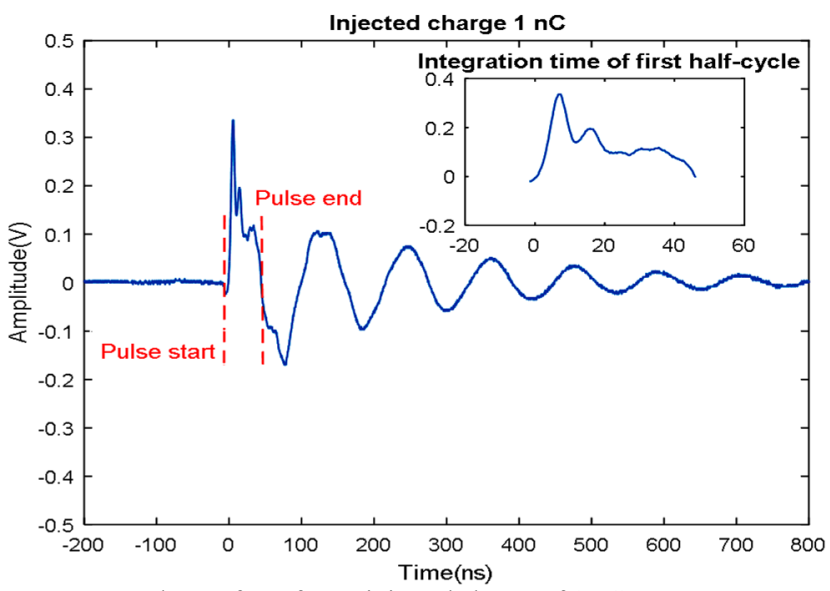

Fig. 7. Measured waveform for an injected charge of $1 \mathrm{nC}$

Table I compares injected charge and charge inferred from the integral of the oscillating waveform over the first half cycle. It also shows the peak voltage of the oscillating waveform. The entries from $1 \mathrm{pC}$ to $20 \mathrm{pC}$ were too noisy to make reliable estimates of apparent charge.

Table I. Relationship between injected charge and calculated charge.

\begin{tabular}{|c|c|c|c|}
\hline $\begin{array}{c}\text { Injected } \\
\text { Charge }\end{array}$ & $\begin{array}{c}\text { First half-cycle } \\
\text { duration } \\
\text { (ns) }\end{array}$ & $\begin{array}{c}\text { Calculated } \\
\text { charge }\end{array}$ & $\begin{array}{c}\text { Peak galvanic } \\
\text { voltage } \\
\text { (V) }\end{array}$ \\
\hline $1 \mathrm{pC}$ & - & - & 0.005 \\
\hline $2 \mathrm{pC}$ & - & - & 0.005 \\
\hline $5 \mathrm{pC}$ & - & - & 0.006 \\
\hline $10 \mathrm{pC}$ & - & $50.8 \mathrm{pC}$ & 0.009 \\
\hline $20 \mathrm{pC}$ & - & $119 \mathrm{pC}$ & 0.007 \\
\hline $50 \mathrm{pC}$ & 48.0 & $206 \mathrm{pC}$ & 0.013 \\
\hline $100 \mathrm{pC}$ & 47.4 & $544 \mathrm{pC}$ & 0.04 \\
\hline $200 \mathrm{pC}$ & 48.4 & $1.5 \mathrm{nC}$ & 0.03 \\
\hline $500 \mathrm{pC}$ & 45.2 & $1.6 \mathrm{nC}$ & 0.10 \\
\hline $1 \mathrm{nC}$ & 47.6 & $5 \mathrm{nC}$ & 0.34 \\
\hline $2 \mathrm{nC}$ & 46.4 & $16 \mathrm{nC}$ & 0.21 \\
\hline $5 \mathrm{nC}$ & 44.3 & $14 \mathrm{nC}$ & 0.88 \\
\hline $10 \mathrm{nC}$ & 46.5 & $35 \mathrm{nC}$ & 3.32 \\
\hline $20 \mathrm{nC}$ & 85.5 & $72 \mathrm{nC}$ & 0.96 \\
\hline $50 \mathrm{nC}$ & 84.6 & & 2.77 \\
\hline $100 \mathrm{nC}$ & 83.1 & & 5.77 \\
\hline & & - & \\
\hline
\end{tabular}


Figure 8 shows the calculated (first half-cycle) charge against the charge injected by the calibrator.

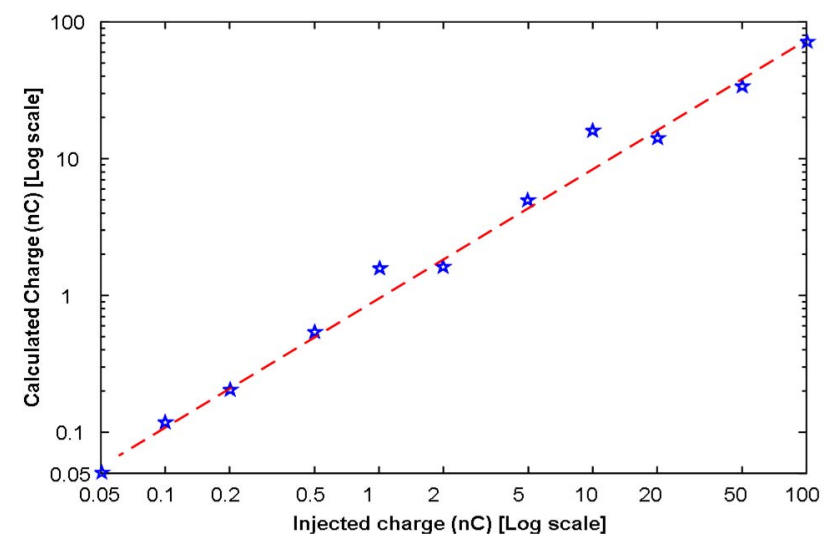

Fig. 8. Calculate charge versus specified charge of charge injection device (setup of Fig. 6).

It is clear from Figure 8 that the first half cycle integral is linearly related to injected charge from the calibrator. By extension we assume that this linear relationship will hold when the charge is injected by a PD event.

It is not obvious that the above can be easily extended to signals radiated by PD events rather than those galvanically conducted to a measurement system. This is, at least in part, because the RF signal at the terminals of a receiving antenna will generally be related to a time-derivative of the PD current pulse rather than a time-integral. Furthermore there are numerous transmission losses that are generally unknown in the case of the radiometrically received PD including the radiation efficiency of the transmitting structure and propagation losses.

Measurements of radiometrically, and galvanically, observed PD signals were undertaken with the measurement system shown in Figure 1. The FSR measurements were made at four distances from the PD source. All the measurements were made using a PD emulator and $50 \mathrm{~Hz}$ power supply voltage of $15 \mathrm{kV}$ RMS. Table II shows the received mean peak voltage amplitude, the calculated charge and calculated effective radiated power (ERP) for the FSR measurements. The ERP was calculated assuming free-space propagation and the known antenna factor of the biconical aerial. The range of the antenna from the PD source was varied from $1 \mathrm{~m}$ to $4 \mathrm{~m}$ in steps of $1 \mathrm{~m}$.
Figure 9 shows the measured FSR peak voltage, the calculated electric field strength and the calculated ERP as a function of measurement range.

In this experiment, the apparent peak ERP varies from 27.1 $\mathrm{dBm}$ at a range of $1 \mathrm{~m}$ to $24.2 \mathrm{dBm}$ at a range of $4 \mathrm{~m}$. In principle the ERP should be independent of distance. If it were independent of distance then, in a radiometric PD location system such as those described in $[7,8]$ there seems to be the possibility of inferring an absolute PD intensity (in terms of apparent charge) from a remote radiometric estimate of ERP.
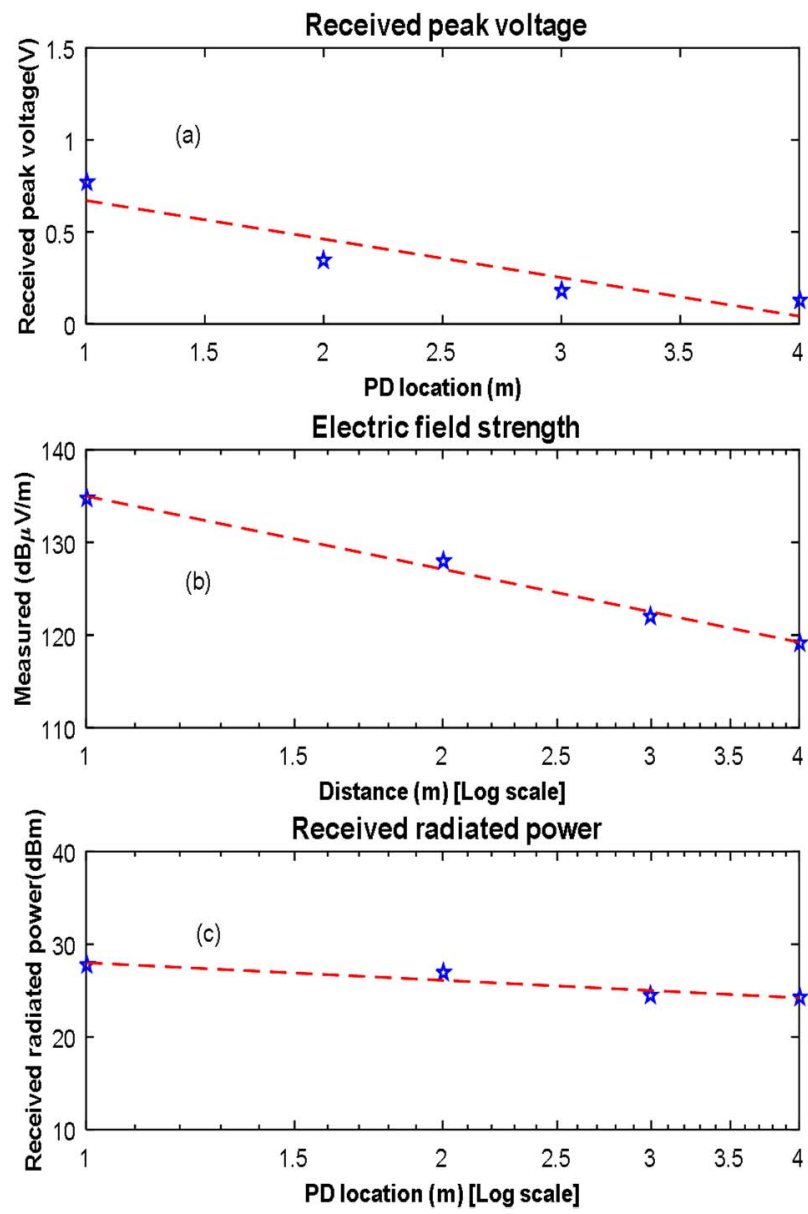

Fig. 9. (a) Received peak voltage, (b) Electric field strength and (c) ERP as a function of PD source - antenna range.

Table II. Concurrent measurements of FSR and galvanic measurements.

\begin{tabular}{|c|c|c|c|c|c|c|c|}
\hline $\begin{array}{l}\text { Power } \\
\text { supply } \\
\text { voltage } \\
(\mathbf{k V})\end{array}$ & $\begin{array}{c}\text { Galvanic } \\
\text { measurement }\end{array}$ & - & $\begin{array}{c}\text { Galvanic mean } \\
\text { peak voltage } \\
\text { (V) }\end{array}$ & $\begin{array}{c}\text { Galvanic mean } \\
\text { peak voltage } \\
(\mathrm{dB} \mu \mathrm{V})\end{array}$ & $\begin{array}{c}\text { Galvanic } \\
\text { measurement } \\
\text { standard deviation } \\
\text { (V) }\end{array}$ & $\begin{array}{l}\text { First half-cycle } \\
\text { duration (ns) }\end{array}$ & $\begin{array}{l}\text { Calculated } \\
\text { charge } \\
(\mathrm{nC})\end{array}$ \\
\hline \multirow{6}{*}{15} & & - & 7.19 & 137.1 & 1.45 & 6.4 & 5.6 \\
\hline & \multirow{5}{*}{$\begin{array}{c}\text { FSR } \\
\text { measurement }\end{array}$} & $\begin{array}{l}\text { Antenna - } \\
\text { emulator } \\
\text { range } \\
\text { (m) }\end{array}$ & $\begin{array}{c}\text { FSR mean peak } \\
\text { voltage } \\
\text { (V) }\end{array}$ & $\begin{array}{c}\text { FSR mean peak } \\
\text { voltage } \\
(\mathrm{dB} \mu \mathrm{V})\end{array}$ & $\begin{array}{l}\text { Peak electric field } \\
\text { strength } \\
(\mathrm{dB} \mu \mathrm{V} / \mathrm{m})\end{array}$ & $\begin{array}{l}\text { Peak ERP } \\
(\mathrm{dBm})\end{array}$ & $\begin{array}{l}\text { Standard } \\
\text { deviation } \\
\text { (V) }\end{array}$ \\
\hline & & 1 & 0.77 & 117.7 & 134.7 & 27.7 & 0.30 \\
\hline & & 2 & 0.35 & 110.8 & 127.9 & 26.8 & 0.09 \\
\hline & & 3 & 0.179 & 105.05 & 122.05 & 24.5 & 0.06 \\
\hline & & 4 & 0.129 & 102.2 & 119.2 & 24.2 & 0.03 \\
\hline
\end{tabular}




\section{DISCUSSION}

The measurement of absolute PD intensity (in $\mathrm{pC}$ ) from a remote free-space radiometric measurement has traditionally thought to have been impractical. If PD intensity can be reliably related to PD ERP, however, then there is the possibility of inferring PD intensity from a measurement of ERP using a radiometric system that locates the PD source. Several issues remain to be investigated before such an absolute radiometric estimate of PD intensity can be realised. Important of these is the anisotropy of the PD radiation and the error in inferred PD intensity which this introduces in practice. (It is thought that, in practice, the gain of the PD radiating structure will be modest.) Also, inferred ERP in the work above has some modest dependence on range. It is possible this apparent variation is due to the propagation environment in which the measurements were carried out (an indoor laboratory) and the fact that the measurements were not carried out unambiguously in the far field. It is felt that the results reported here are sufficiently encouraging, however, to pursue this work further.

\section{Acknowledgment}

The authors acknowledge the Engineering and Physical Sciences Research Council for their support of this work under grant EP/J015873/1.

\section{References}

[1] B. Hampton, "UHF diagnostics for gas insulated substations," in High Voltage Engineering. Eleventh International Symposium on (Conf. Publ. No. 467), 1999, pp. 6-16.

[2] A. Jaber, P. Lazaridis, Y Zhang, D Upton, H Ahmed, U Khan, B Saeed, P Mather, M F Q Vieira, R Atkinson, M Judd, and I A Glover, "Comparison of contact measurement and free-space radiation measurement of partial discharge signals," in Automation and Computing (ICAC), 2015 21st International Conference on 2015,pp. 1-4. IEEE.

[3] HVPD. Available: http://www.hvpd.co.uk/ (accessed on November 2015).

[4] E. Lemke, S. Berlijn, E. Gulski, M. Muhr, E. Pultrum, T. Strehl, W. Hauschild, J. Rickmann, G. Rizzi: 'Guide for partial discharge measurements in compliance to IEC 60270', CIGRE Technical Bochure 366, WG D1.33, December 2008.

[5] I. E. Commission, High-voltage Test Techniques: Partial Discharge Measurements: International Electrotochnical Commission, 2000.

[6] HV PD, "Introduction to Partial Discharge (PD)," 2015.

[7] Y. Zhang, D. Upton, A. Jaber, H. Ahmed, B. Saeed, P. Mather, P. Lazaridis, A. Mopty, C. Tachtatzis, R. Atkinson, M. Judd, M F Q Vieira, and I A Glover, "Radiometric Wireless Sensor Network Monitoring of Partial Discharge Sources in Electrical Substations," International Journal of Distributed Sensor Networks, vol. 2015, 2015.

[8] J.M. Neto, Y. Zhang, A. Jaber, M. Zhu, M. Judd, R. Atkinson, J. Soraghan, J.S. Neto, M.F. Vieira, I.A. Glover,"Radiometric location of partial discharge sources for the future smart grid," in General Assembly and Scientific Symposium (URSI GASS), 2014 XXXIth URSI, 2014, pp. $1-4$. 